\title{
Real-Time Microwave, Dielectric, and Optical Sensing of Lincomycin and Tylosin Antibiotics in Water: Sensor Fusion for Environmental Safety
}

\author{
Alex Mason (D, ${ }^{1}$ Matteo Soprani, ${ }^{2}$ Olga Korostynska, ${ }^{3}$ Abitami Amirthalingam, ${ }^{3}$ Jeff Cullen, ${ }^{3}$ \\ Magomed Muradov, ${ }^{3}$ Estefania Núnez Carmona, ${ }^{2}$ Giorgio Sberveglieri, ${ }^{2}$ \\ Veronica Sberveglieri ${ }^{\circ},{ }^{4}$ and Ahmed Al-Shamma'a ${ }^{3}$ \\ ${ }^{1}$ Animalia, Norwegian Meat and Poultry Research Centre, Økern PO Box 396, 0513 Oslo, Norway \\ ${ }^{2}$ Department of Information Engineering, University of Brescia, Brescia, Italy \\ ${ }^{3}$ Faculty of Engineering and Technology, Liverpool John Moores University, Liverpool, UK \\ ${ }^{4}$ CNR-IBBR, Via Madonna del Piano 10, 50019 Sesto Fiorentino (FI), Italy \\ Correspondence should be addressed to Alex Mason; alex.mason@animalia.no
}

Received 21 March 2018; Revised 4 July 2018; Accepted 19 July 2018; Published 25 September 2018

Academic Editor: Manel del Valle

Copyright (C) 2018 Alex Mason et al. This is an open access article distributed under the Creative Commons Attribution License, which permits unrestricted use, distribution, and reproduction in any medium, provided the original work is properly cited.

\begin{abstract}
Antibiotics are widely used to prevent and treat bacterial infections in livestock animals, aquaculture, and humans. However, the unconditional use of those drugs as a growth promoter for livestock animals and the wrong usage as a treatment for infections in humans has led to high antibiotics pollution, especially in water resources. The elevated presence of antibiotics in water has resulted in the phenomenon known as the bacterial antibiotics resistance. To prevent ecological catastrophe, continuous realtime monitoring of water sources is necessary. The aim of this research work is to compare the abilities of three different techniques: novel electromagnetic wave spectroscopy, UV-Vis spectrophotometry, and capacitance sensing system for the realtime detection and quantification of antibiotics in water. Tylosin and lincomycin antibiotics were selected to the study, as both are regularly found in water sources. Two novel microwave sensor configurations were used: a planar sensor with interdigitated electrode pattern and a hairpin resonator sensor, as a means of real-time water analysis. Reflected $S_{11}$ power signals were analyzed in $\mathrm{GHz}$ frequency range for microwave sensors. In parallel, UV-Vis spectrophotometry was used, where change in the optical absorbance was used as an indicator of water pollution, whereas change in the value of a capacitance in low frequency range has signalled the change in the dielectric properties of the solution. It was found that in all cases the changes in the measured parameters were dependent on both the type of antibiotic present in water and on its concentration. Fusion of all these techniques into a comprehensive sensing platform provides adequate real-time assessment of the water pollution with antibiotics and would allow adequate management of environment for safety and sustainable development. In particular, the lowest lincomycin samples' concentration, $0.25 \mu \mathrm{g} / \mathrm{l}$, was measured with a hairpin resonator sensor, while the lowest tylosin samples' concentration, $0.20 \mu \mathrm{g} / \mathrm{l}$, was measured with an IDE sensor. Since concentration in groundwater were $0.36 \mu \mathrm{g} / \mathrm{l}$ of lincomycin and $1.5 \mu \mathrm{g} / \mathrm{l}$ of tylosin, it is demonstrating a high-sensing platform utility.
\end{abstract}

\section{Introduction}

Antibiotics have been used for almost a century as the main treatment against the bacterial infections in humans, livestock animals, and aquaculture [1]. The antibiotics consumption by humans and livestock animals is dramatically increased, and these are used not only for treatment but also for disease prevention as well, mainly for economic reasons in farming. Antibiotics are also essential for controlling bacterial diseases of plants [2]. The global human consumption of antibiotics has risen by $30 \%$ between 2000 and 2010; moreover, by 2030 , this figure is expected to rise 105,600 tons to 
meet the demands of a projected 8.5 billion human population [3]. In livestock, at least 63 tons of antibiotics were consumed in 2010.

In livestock, antibiotics have a double role as growthpromoters and as preventive treatment against infections. The term "growth-promoter" describes any drugs used to "help growing animals digest their food more efficiently, get maximum benefit from it, and allow them to develop into strong and healthy individuals" according to the National Office of Animal Health (NOAH). The balance between promoting growth and ensuring the animal health is often overshadowed by the economic factors, where animals are given antibiotics in much higher doses than necessary, to minimise the probability of possible bacterial infections. Notably, human and animal bodies do not completely absorb all the antibiotics, and unused amounts of it end up polluting water sources. As a result, a subsequent effect concerning the growth-promoter is the environment pollution of water and soil with antibiotics residuals. Furthermore, traceable amounts of antibiotics can be found in meat, milk products, and even plants that come in contact with contaminated water. This, in turn, leads to a danger for human health and overall environment.

The antibiotics abuse has led to a serious hazard for health and environment: the antibiotics resistance [4, 5], contributing to a number of deaths, where inadequate treatment was received [6]. An antibiotic resistant occurs when bacteria mutate and become fully resistant to antibiotics which previously could treat it. Bacteria are able to reach the resistance in three ways: natural resistance in certain types of bacteria; genetic mutation or by one species acquiring resistance from another. Particularly, the last two are the cause of the antibiotics environmental pollution. Bacteria with antibiotics resistance are able to reach people and animals through food, water, soil, and air.

Untreated water carries great number of antibiotics [7]; therefore, its adequate treatment is a key step to reduce the antibiotics pollution [8] and ensure environmental safety. In water treatment, it is fundamental that antibiotics presence and concentration are monitored continuously. Even lowest concentrations of antibiotics in water can cause deleterious long-term environmental effects; therefore, new tool and techniques are necessary to analyze them. These must be extremely sensitive and operate in real time to provide efficient environmental management platform.

Several methods have been proposed to detect antibiotics and antibiotic-resistant bacteria in wastewater treatment process [9] such as high-performance liquid chromatography (HPLC), tandem mass spectroscopy (MS/MS), ultra-highperformance liquid chromatography-tandem mass spectroscopy (UPLC-MS/MS), and molecular biological method (PCR). All these tools and techniques are extremely sensitive but present some important issues: high purchase, operation, and maintenance costs, they are not portable so, it is not possible to analyze the sample directly on the sample site, analysis take a long period of time and they require the presence of highly skilled operators.

The aim of this research work is to compare three different techniques such as electromagnetic wave spectroscopy,
$\mathrm{UV}-\mathrm{V}$ is spectrophotometry, and capacitance sensing system for the real-time monitoring and detection of residual antibiotics pollution in water [10]. In order to realize a novel comprehensive sensing platform for real-time water quality analysis, the approach of fusing all these techniques into a single system with advanced sensitivity and reliability was used, so that the water treatment process can be managed in accordance with the present antibiotics.

In this study, to assess the feasibility of this approach, two different antibiotics, namely, lincomycin and tylosin were used. Tylosin is a fermentation product of Streptomyces fradiae [11]. It is a broad spectrum antibiotics used in livestock animals for the treatment of infections caused by Gram-positive and a limited range of Gram-negative bacteria [12]; it is used as a growth promoter in some species too. Lincomycin is a fermentation product of Streptomyces lincolnensis [13]. At present, it is used only in patients allergic to penicillin antibiotics or where bacteria have developed resistance because of its higher toxicity. Antibiotics tylosin were found in $48 \%$ of 139 steam water tested in 30 states according to the U.S. Geological Survey [14]. Antibiotics entering the environment could potentiality alter bacterial population and their activity in sediment water, thus affecting biodegradation, nutrient cycling, and water quality. In addition, there is a concern that antibiotics in the environment may induce antibiotic resistance, resulting in adverse human health effects.

The following section provides critical overview of the current methods used for antibiotic detection, focusing on those that are particularly used for the chosen antibiotics. This analysis demonstrates that the current methods are inadequate for real-time environmental monitoring purposed and justifies the need to develop novel sensing solutions.

\section{Modern Methods of Antibiotics Detection in Water}

Trace concentrations of antibiotics in wastewater, various water sources, and some drinking waters can be currently found worldwide. Concentrations in surface waters and groundwater were $0.36 \mu \mathrm{g} / \mathrm{l}$ of lincomycin and $1.5 \mu \mathrm{g} / \mathrm{l}$ of tylosin [15], whereas concentrations in treated water were generally below $5 \times 10^{-2} \mu \mathrm{g} / \mathrm{l}$ (or $50 \mathrm{ng} / \mathrm{l}$ ) [16].

In current methods of detecting antibiotics in wastewater, high-performance liquid chromatography (HPLC) and tandem mass spectrometry (MS/MS) were used after the extraction process. For example, in an approach to detect occurrence of several antibiotics in hospital, residential, dairy, and municipal wastewater using HPLC and MS/MS, lincomycin was detected with some other antibiotics in hospital and dairy wastewater [17].

Ultra-high-performance liquid chromatography-tandem mass spectrometry (UPLC-MS/MS) method was developed to detect selected pharmaceutical antibiotics in wastewater, and the method showed sensitive, reliable, and accurate performance to the three antibiotics [18].

A molecular biological method of PCR was used to find antibiotic-resistant bacteria in wastewater biofilms and also in drinking water biofilms [19]. PCR detected vancomycin- 


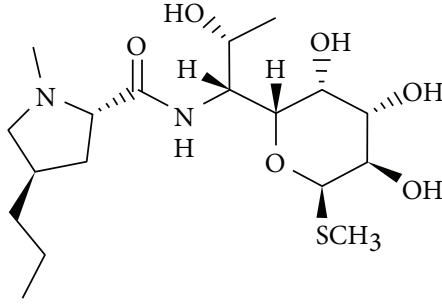

(a)

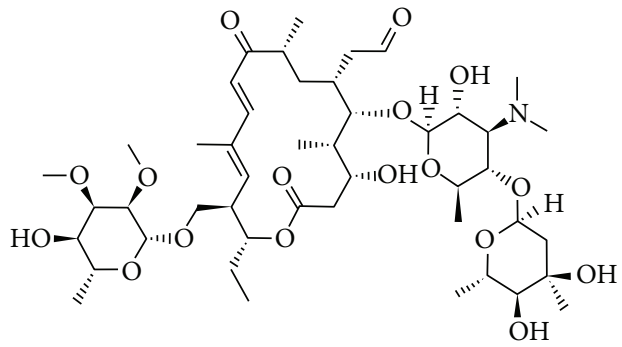

(b)

Figure 1: (a) Lincomycin antibiotic chemical structure; (b) tylosin antibiotic chemical structure.

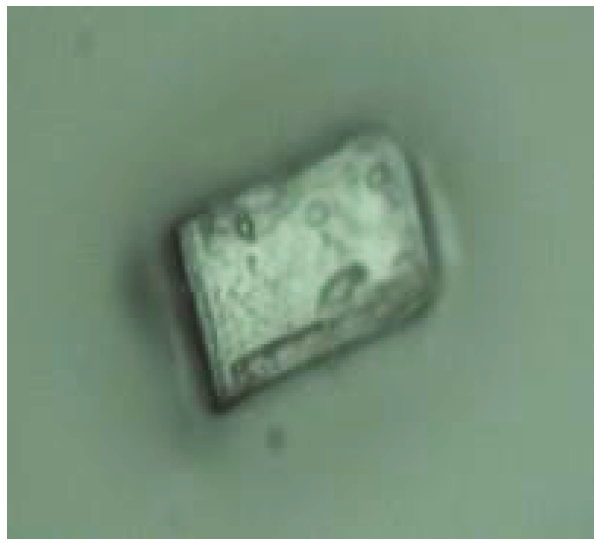

(a)

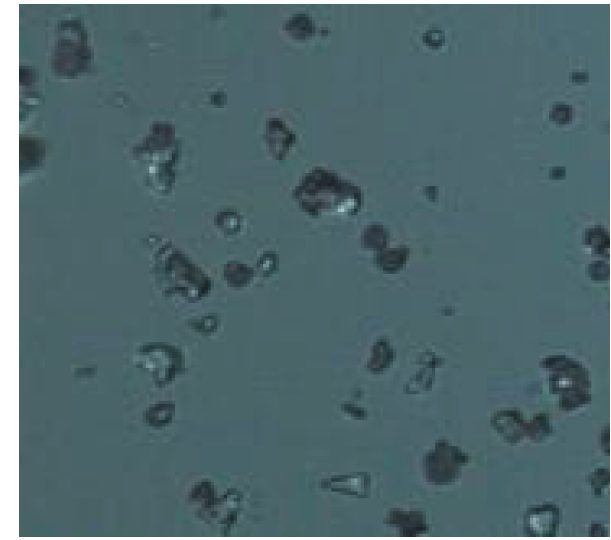

(b)

FIGURE 2: Optical image of lincomycin (a) and tylosin (b) particles taken with ZEISS Scope.A1 20x/0.4 EC-EPIPLAN microscope.

resistant enterococci in wastewater and in drinking water and also detected methicillin-resistant staphylococci in hospital wastewater. In another instance, the spread of antibiotic resistance genes in wastewater treatment systems and their occurrence in surface and drinking water systems were revealed by quantitative PCR (qPCR) assay [20].

On the development of sensors for detecting a specific antibiotic in wastewater effluents as well as in natural water, an electrochemical sensor in a form of a porous nafion multiwalled carbon nanotube composite film electrode, an electrochemical sensor, was developed to detect the antibiotic ciprofloxacin (CFX) [21]. The sensor was selective only for ciprofloxacin even with the presence of other antibiotics and nontarget water constituents. Therefore, it was recommended to be applicable in wastewater effluents and in natural waters to detect ciprofloxacin.

HPLC method was compared with enzyme-linked immunosorbent assay (ELISA) for the detection of tylosin and tylosin-related compounds in water [22]. As a result, HPLC detected a lower concentration of tylosin compound, while ELISA detected most of the tylosin-related compounds.

The combination of ELISA with HPLC/MS or with other conventional detection methods was suggested to be potential for sensitive and specific detection of tylosin-related compounds. HPLC with MS/MS is the commonly and widely used technology in detecting antibiotics in wastewater as well as in surface water. However, this method is too expensive and time-consuming for real-time water pollution monitoring at multiple locations.

This research aims to address this issue by assessing the capabilities of UV-Vis spectrophotometer and impedance analyzer to detect the presence, type, and concentration of lincomycin and tylosin in water in real time.

\section{Materials and Methods}

The chemical structure of tylosin $\left(\mathrm{C}_{46} \mathrm{H}_{34} \mathrm{NO}_{17}\right)$ and lincomycin $\left(\mathrm{C}_{18} \mathrm{H}_{34} \mathrm{~N}_{2} \mathrm{O}_{6} \mathrm{~S}\right)$ is shown in Figures $1(\mathrm{a})$ and $1(\mathrm{~b})$, respectively. Figure 2 depicts optical image of the original powder for each antibiotic. The concentrations of these compounds are different between untreated and treated water. In untreated water, the concentrations are $0.36 \mu \mathrm{g} / \mathrm{l}$ of lincomycin and $1.5 \mu \mathrm{g} / \mathrm{l}$ of tylosin, whereas concentrations in treated water were generally below $5 \times 10^{-2} \mu \mathrm{g} / \mathrm{l}$ (or $50 \mathrm{ng} / \mathrm{l}$ ) [16]

Tylosin and lincomycin aqueous solutions samples were prepared in two different steps. The first one was the preparation of both antibiotics stock solution at the final concentrations of $2.5 \times 10^{5} \mu \mathrm{g} / \mathrm{l}$ and $2.0 \times 10^{5} \mu \mathrm{g} / \mathrm{l}$, respectively. In order to do that, $25 \times 10^{2} \mu \mathrm{g}$ and $20 \times 10^{2} \mu \mathrm{g}$ of respective antibiotics were dissolved in $10 \mathrm{ml}$ of distilled water. In the final step, through the serial dilutions technique, four different concentrated antibiotic solutions were prepared, from $2.0 \times 10^{5} \mu \mathrm{g} / \mathrm{l}$ to $0.20 \mu \mathrm{g} / \mathrm{l}$ of tylosin and from $2.5 \times 10^{5} \mu \mathrm{g} / \mathrm{l}$ to $0.25 \mu \mathrm{g} / \mathrm{l}$ of lincomycin. 


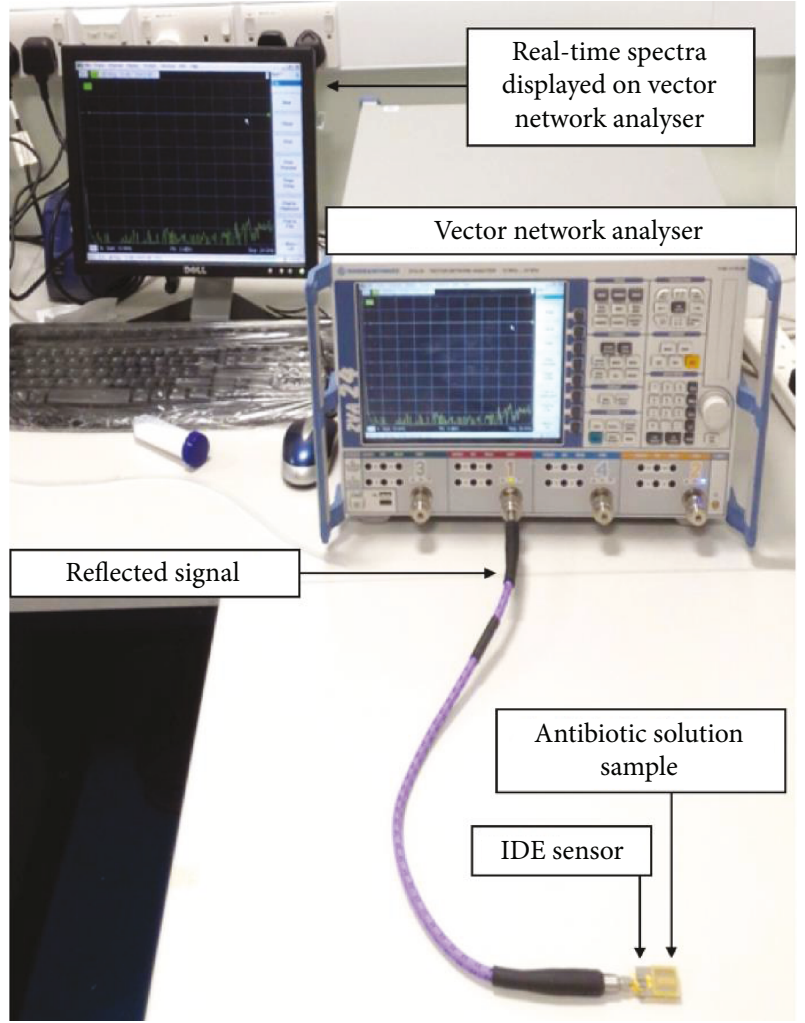

Figure 3: Vector network analyzer (VNA) connected to a planar IDE sensor.

In all cases, the solutions remain transparent and the water pollution is invisible for human eye. This confirms the need for novel sensing system to trace the presence of water pollutants for environmental safety. All measurements were performed on the same day the samples were prepared.

3.1. Microwave Sensor. To assess the capabilities of the microwave sensors [23] to act as a real-time platform for monitoring residual concentration of tylosin and lincomycin in aqueous solution, the system shown in Figure 3 was used.

Notably, the results were obtained using an IDE sensor for tylosin and a hairpin resonator sensor for Lincomycin [24], both sensors connected to a Rohde and Schwarz ZVA24 vector network analyzer (VNA). Furthermore, a comparison between the microwave sensors and other two different sensor technologies such as optical detection and capacitance sensing system was performed in order to observe which is the most efficient technology for this kind of analysis.

A specific microwave band was generated from the VNA depending on the sensors used so as to permit the interaction between the sample, inside the sensor holder and, the electromagnetic (EM) waves. This interaction changes depending on the specific properties of the sample [25]. The EM waves in contact with the sample are therefore influenced by the specific properties of it such as the permittivity, generate a unique response signal spectrum measurable through the VNA, using the reflected signal $S_{11}$.
The EM field generated from the two sensors are a constant; what varies is the two antibiotics' concentration inside the aqueous solutions; for these reasons, the obtained spectrum interpretation allows the characterization of the materials' properties [26]. In other words, changes in the spectrum profile caused by the different samples' concentrations are linked to the properties of the antibiotics present in water samples and are unique for each pollutant.

The IDE sensor has a sample holding capacity of $400 \mu \mathrm{l}$, and the microwave band used was from $10 \mathrm{MHz}$ to $15 \mathrm{GHz}$, while the hairpin resonator sensor has a sample capacity of $200 \mu \mathrm{l}$, and the microwave band used was from to $10 \mathrm{MHz}$ to $4 \mathrm{GHz}$.

3.2. Capacitance Sensing System. For what concerns the capacitance sensing approach, a capacitor sensing system connected to a Hameg Industries programmable LCR bridge HM8118 was used, as illustrated in Figure 4(a). In this experiment, two cylindrical rods of a typical SMA connector were used as the electrodes for capacitance measurements in $20 \mathrm{~Hz}-200 \mathrm{kHz}$ frequency range $[27,28]$. The electrical field is formed between the two electrodes through the voltage applied across them (Figure 4(b)).

The capacitance describes the effects on the electric field due to the space between the two plates, and it is determined by the geometry of the conductors, the distance between the electrodes, and the dielectric material [29]. Value of capacitance can be found according to

$$
C=\frac{\pi \varepsilon_{0} \varepsilon_{r}}{\ln (\boldsymbol{d} / \boldsymbol{r})} L
$$

where $C$ is the capacitance in farads $(\mathrm{F}), \varepsilon_{0}$ is the relative static permittivity (dielectric constant) of the material between the plates, $\varepsilon_{r}$ is the permittivity of free space, which is equal to $8.854 \times 10^{-12} \mathrm{~F} / \mathrm{m}, L$ is the rod length in meters, $d$ is the separation distance (in meters) of the two rods, and $r$ is the radius of the rod in meters.

A capacitive sensor uses the changes in the value of the dielectric constant, manifested as a change in electrical signal, as an indicator of water pollution, in this case with various antibiotics [30]. Since the geometry of conductor and the distance between the electrodes are constant, the dielectric constant represents the only variable [30]. That means a capacitance change depending on the different solutions concentrations.

The experiments provide a capacitance measurement for the antibiotics solutions at different concentrations and were completed in regulated temperature and humidity conditions. The frequency range used for the measurement of capacitance in the antibiotics solutions was from $20 \mathrm{~Hz}$ to $200 \mathrm{kHz}$; they are generated from an LCR bridge tool, which was connected to a desktop computer for data acquisition via a bespoke LabVIEW interface. The measurements were taken three times for each sample with 3 -second interval and then averaged.

In order to do the analysis, $400 \mu \mathrm{l}$ of solution were put inside the sample holder, then the electrodes were immersed 


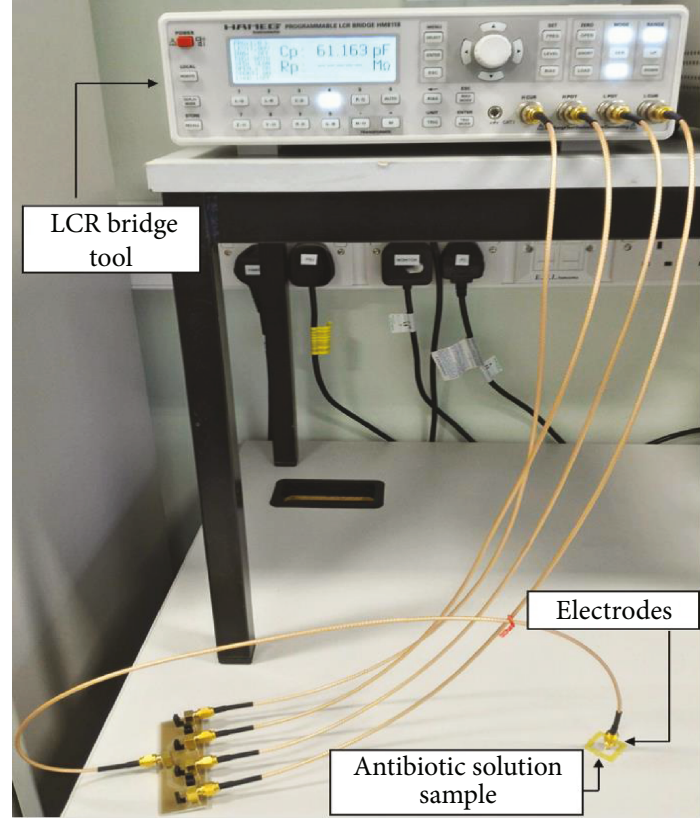

(a)

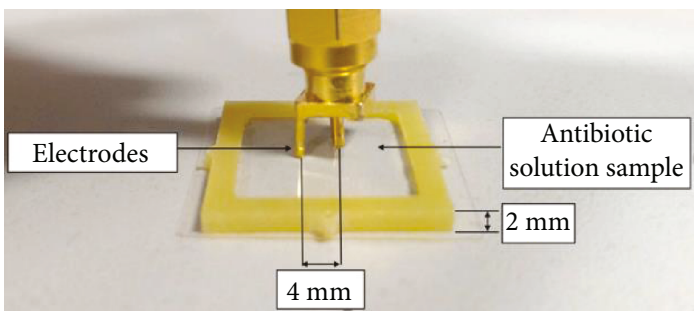

(b)

FIgURE 4: (a) Capacitance measurement of antibiotics solutions; (b) capacitor composed of two cylindrical rods electrodes.

inside the solution samples, and finally, the capacitance values were repeatedly measured for the whole range of frequencies. The graphs in the next section present averaged results, with max $5 \%$ variations between the samples.

3.3. Optical Measurements. UV-Vis spectroscopy is an analytical technique used for the quantitative analysis of different analytes such as metal ions, organic compounds, and biological macromolecules. It regards the measurement of adsorption of electromagnetic radiation in the ultraviolet (185$400 \mathrm{~nm}$ ) and visible (400-800 nm) spectral region; this technique is regulated by the Beer-Lambert law. It reports the change of the light properties with respect to the material through which the light is traveling. The law is described by

$$
A=\varepsilon c l,
$$

where $A$ in the absorbance, $\varepsilon$ is the extinction coefficient $\left(\mathrm{M}^{-1} \mathrm{~cm}^{-1}\right), c$ is the sample's concentration in molarity $(\mathrm{M})$, and $l$ is the path length in centimeters $(\mathrm{cm})$.

In other words, the absorbance of a solution is directly proportional to the concentration of the absorbing species in the solution and the path length.

For the experimentation, a UV-Vis spectrophotometer tool was used. It is able to measure the intensity of the light passing through a sample $(I)$ and compares it to the intensity of light before it passes through the sample $\left(I_{0}\right)$. The ratio $I / I_{0}$ represents the transmittance $(T)$. Absorbance is based on the transmittance as is shown in

$$
\boldsymbol{A}=-\log \left(\frac{\% \boldsymbol{T}}{100 \%}\right)
$$

For the optical measurements, a Jenway 7315 UV-Vis spectrophotometer was used; the optical measurements were performed with the full-range wavelength from $200 \mathrm{~nm}$ to $1000 \mathrm{~nm}$.

\section{Results and Discussion}

This section presents the results using the three different techniques, namely, microwave sensors, a capacitance sensing system, and an UV-Vis spectrophotometer for real-time monitoring of residual concentration of tylosin and lincomycin in an aqueous solution. Each technique is presented independently, and then the frequency regions and the operational parameters of each technique are identified to integrate them into unique platform with superior selectivity and sensitivity for the chosen antibiotics.

4.1. Optical Measurements. The maximum absorbance for the antibiotics was observed in the range between $200 \mathrm{~nm}$ and $400 \mathrm{~nm}$ as shown in Figures 5(a) and 5(b). To trace the change in the optical absorption in UV-Vis range with increasing concentration of lincomycin (Figure 6(a)) and tylosin (Figure 6(b)), calibration curves at $220 \mathrm{~nm}$ and $290 \mathrm{~nm}$, respectively, can be used. This set of measurements served as a benchmark for validating concentrations of antibiotics and for comparison of sensitivities of standard optical and novel capacitance sensing approaches. With UV-Vis, the type of antibiotic and its concentration can be identified at high concentration and also at a specific wavelength. There is not any positive absorbance observed at low concentrations. Therefore, it is not possible to distinguish between these two antibiotics at low concentrations in the same solution. 


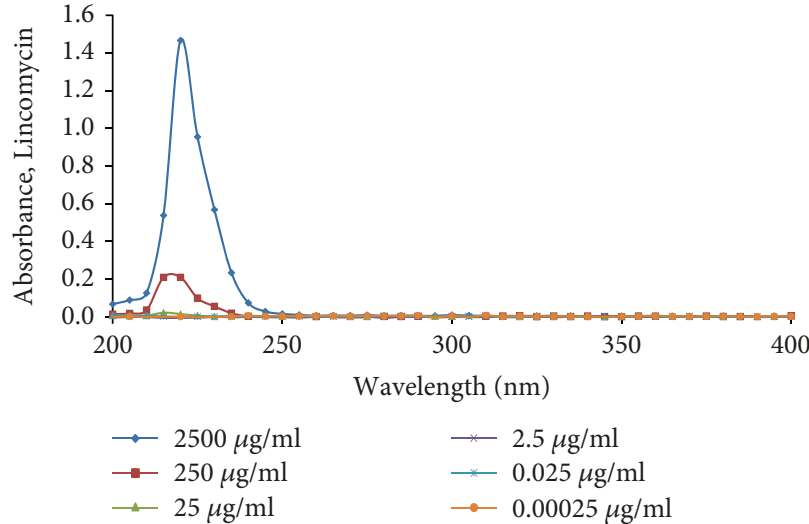

(a)

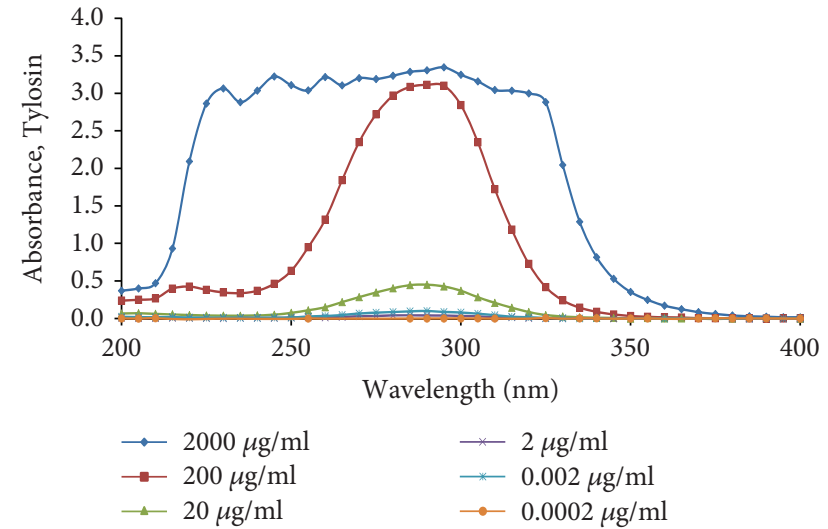

(b)

Figure 5: (a) Change in the absorbance of (a) lincomycin and (b) tylosin solutions in the range between $200 \mathrm{~nm}$ to $400 \mathrm{~nm}$ with concentration.

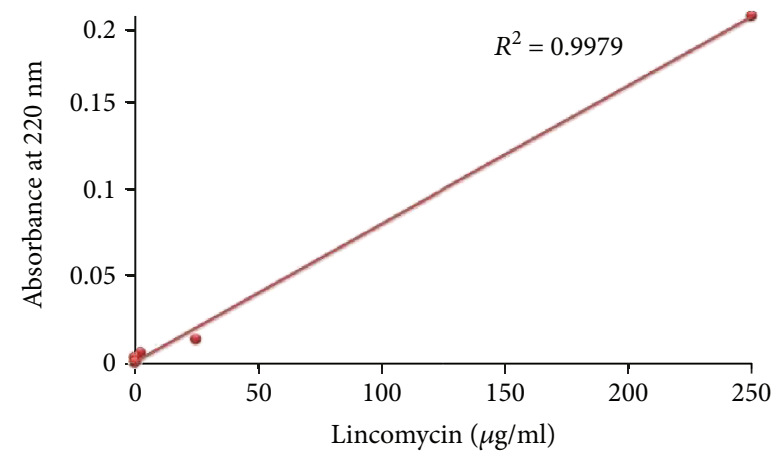

(a)

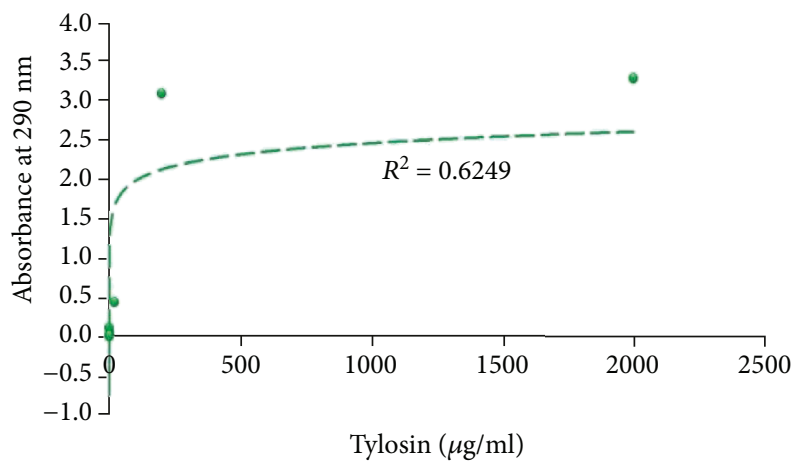

(b)

Figure 6: (a) Absorbance change with lincomycin concentration at $220 \mathrm{~nm}$; (b) absorbance change with tylosin concentration at $290 \mathrm{~nm}$.

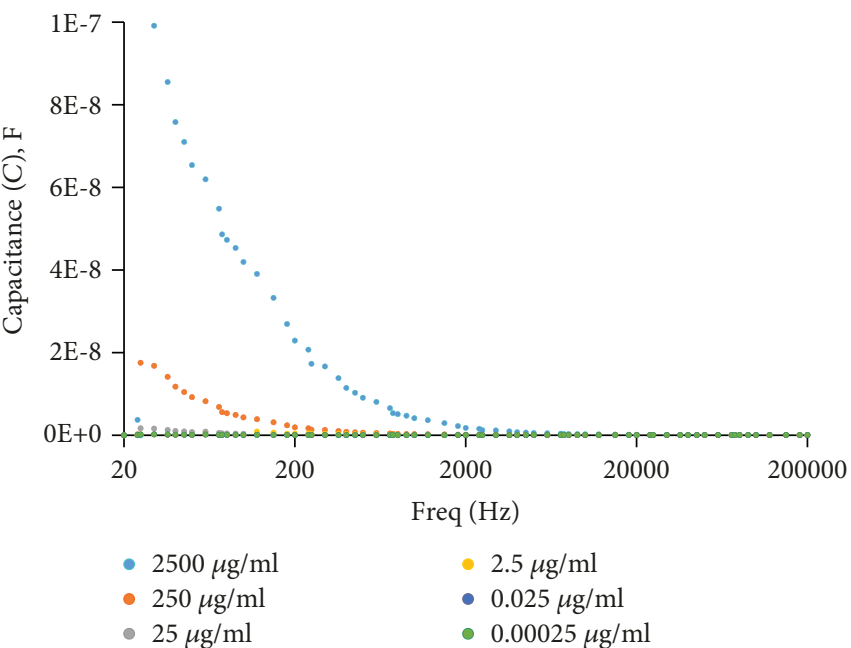

(a)

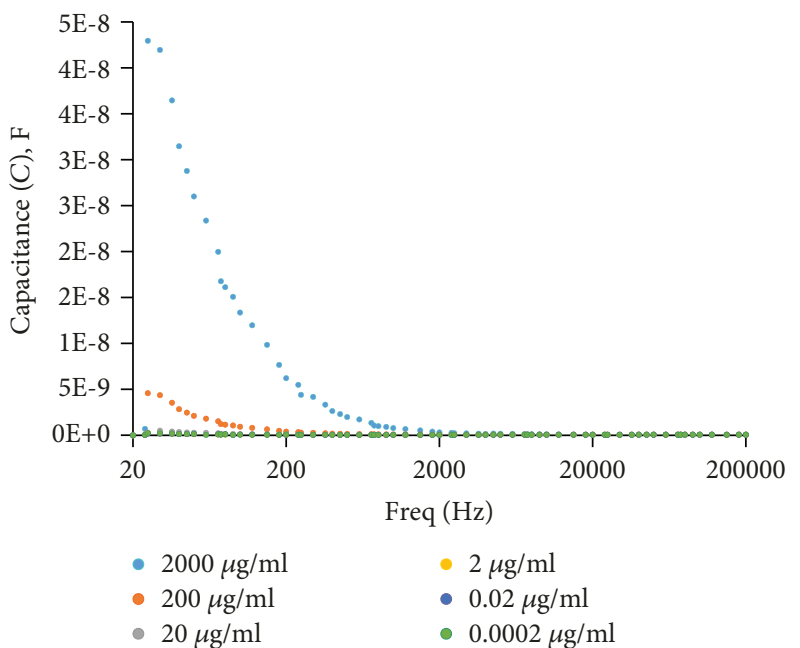

(b)

FIGURE 7: (a) Frequency dependence of lincomycin solutions capacitance in $20 \mathrm{~Hz}-20 \mathrm{kHz}$ range; (b) frequency dependence of tylosin solutions capacitance values in $20 \mathrm{~Hz}-20 \mathrm{kHz}$ range.

4.2. Capacitance Sensing System Results. To assess the effect of various concentrations of lincomycin and tylosin antibiotics on dielectric properties of the solutions at low frequencies, an approach described in Section 3.2 was used.
Figures 7(a) and 7(b) illustrate the frequency dependence of the capacitance values in $20 \mathrm{~Hz}-20 \mathrm{kHz}$ range for lincomycin and tylosin antibiotics, respectively. In line with previously described optical measurements, once the area of the spectra 


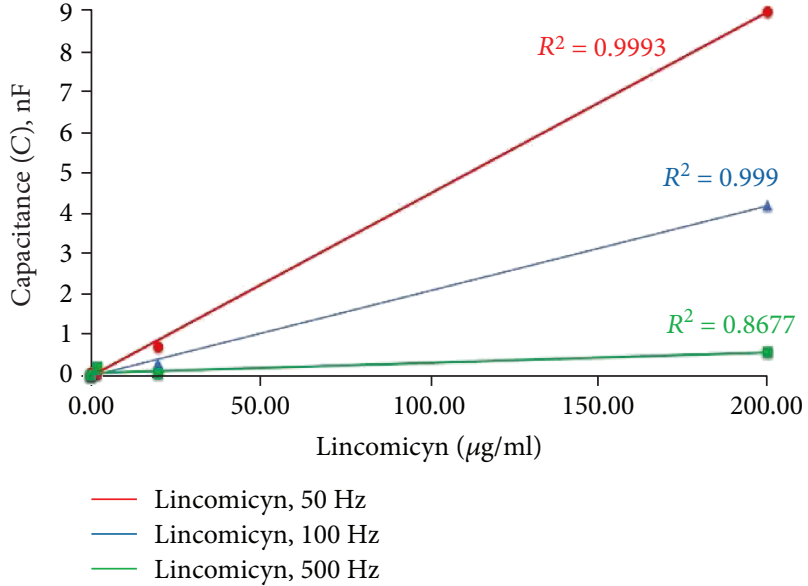

(a)

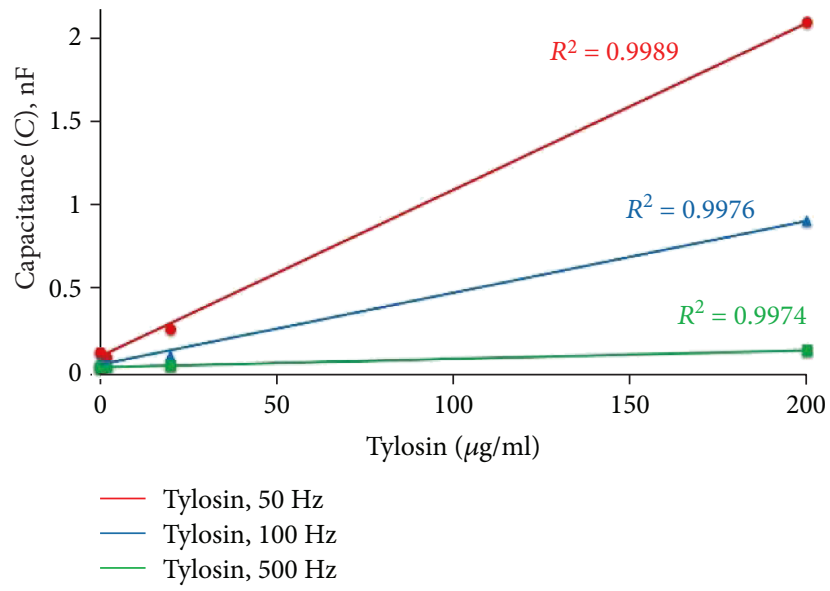

(b)

FIgURE 8: Change in capacitance with (a) lincomycin and (b) tylosin at the three frequencies selected: $50 \mathrm{~Hz}, 100 \mathrm{~Hz}$, and $500 \mathrm{~Hz}$.

that is the most representative of the effect of various concentrations on the capacitance values of the solution is identified, the measurements can be simplified into a calibration curve at a specific preselected frequencies.

To ensure repeatability of the results, five different solutions at different concentrations were used for both antibiotics. In particular: $2 \times 10^{-4} \mu \mathrm{g} / \mathrm{ml}, 2 \times 10^{-2} \mu \mathrm{g} / \mathrm{ml}$, $2 \mu \mathrm{g} / \mathrm{ml}, 20 \mu \mathrm{g} / \mathrm{ml}$, and $2 \times 10^{2} \mu \mathrm{g} / \mathrm{ml}$. For this developed capacitance sensing system, the three selected frequencies for both antibiotics were $50 \mathrm{~Hz}, 100 \mathrm{~Hz}$, and $500 \mathrm{~Hz}$, as portrayed in Figures 8(a) and 8(b). These figures also provide $R^{2}$ values for each calibration curve. Please note that since the difference between the highest $\left(2 \times 10^{2}\right)$ and the lowest concentration $\left(2 \times 10^{-4}\right)$ is large and, in the graph, all the samples' concentration are represented, the last three low concentrations seem overlapped. Based on the above results, one can firmly conclude that the capacitance sensing system was able to distinguish between tylosin and lincomycin (Figure 9).

4.3. Microwave Sensors Response. The graphs in Figures 10(a) and $10(\mathrm{~b})$ show the repeatability of the measurements conducted with the bespoke electromagnetic wave sensors. A tylosin sample at the concentration of $0.20 \mu \mathrm{g} / \mathrm{l}$ and a sample of lyncomycin at the concentration of $0.25 \mu \mathrm{g} / \mathrm{l}$ were prepared and measured three times using the full-range frequencies: $0 \mathrm{~Hz}-1.5 \times 10^{10} \mathrm{~Hz}$ for IDE sensor and $0 \mathrm{~Hz}-4 \times 10^{9} \mathrm{~Hz}$ for hairpin resonator sensor at the same conditions. In particular, Figure 10(a) demonstrated the high repeatability about the analysis of the lowest concentration of tylosin. It means that the sensors used have a high level of reliability, and consequently, the experimental error is extremely low. For what concerns lincomycin, similar results for the lowest antibiotics concentration were obtained (Figure 10(b)). These figures also illustrate the effect of the sensor design (IDE and hairpin, resp.) on the reflected electromagnetic spectra measured from the sensor.

In order to find a frequency, which can be used as a calibration reference for a linear dependence between the

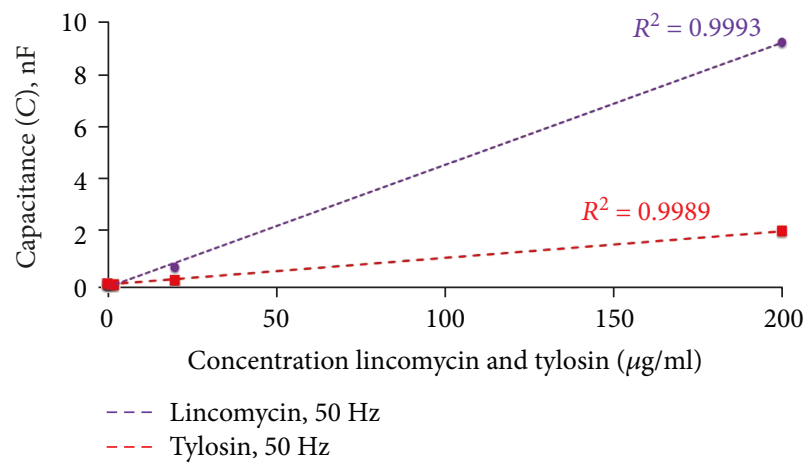

Figure 9: Change in capacitance with tylosin and lincomycin at $50 \mathrm{~Hz}$.

reflected power $S_{11}$ and the antibiotics samples at different concentrations, each frequency range was examined in details. Particularly, it was selected within the entire fullrange used for the experimentation, where the distinction between samples was maximum. For tylosin, the frequency range was from $8.7 \times 10^{9} \mathrm{~Hz}$ to $8.8 \mathrm{GHz}$ (Figure $11(\mathrm{a})$ ) while for lincomycin from $1.767 \mathrm{GHz}$ to $1.76 \mathrm{GHz}$ (Figure 11(b)).

A linear dependence of the $S_{11}$ transmitted microwave signal on antibiotics was found at $8.7 \times 10^{9} \mathrm{~Hz}$ for $400 \mu \mathrm{l}$ solution of tylosin and at $1.8 \times 10^{9} \mathrm{~Hz}$ for $200 \mu \mathrm{l}$ solution of lincomycin; the graphs are shown in Figures 12(a) and $12(\mathrm{~b})$. The evaluation linear indicator $R^{2}$ is higher for the two antibiotics: $R^{2}=0.9277$ for tylosin and $R^{2}=$ 0.8122 for lincomycin. Importantly, once the frequency range where the system is selectively sensitive to a particular antibiotic is known, the expensive vector network analyzer equipment could be replaced with custom-made hand-held electronics units for portable applications, where the measurements can take place anywhere and provide on-line results.

Figure 13 confirms that the IDE sensor is highly sensitive for qualitative analysis, as it was able to discriminate the two antibiotics. In order to have a complete overview about the 


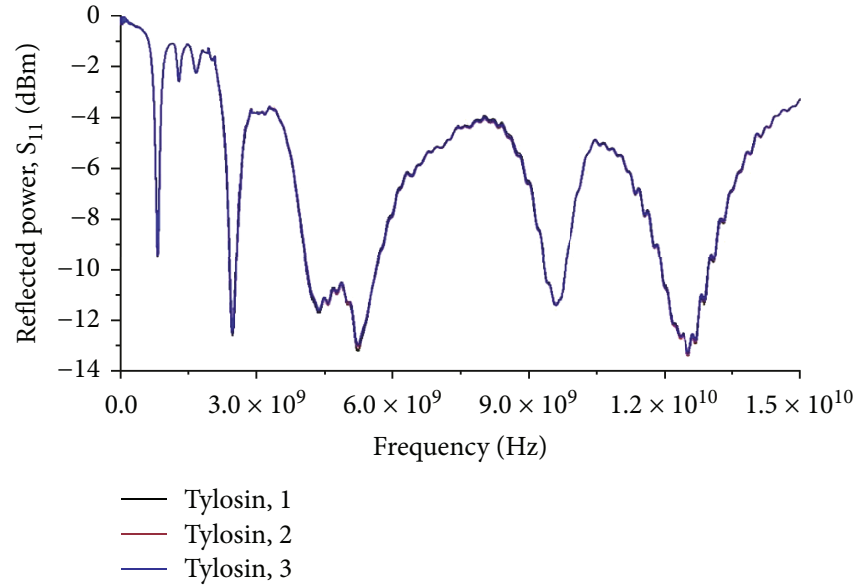

(a)

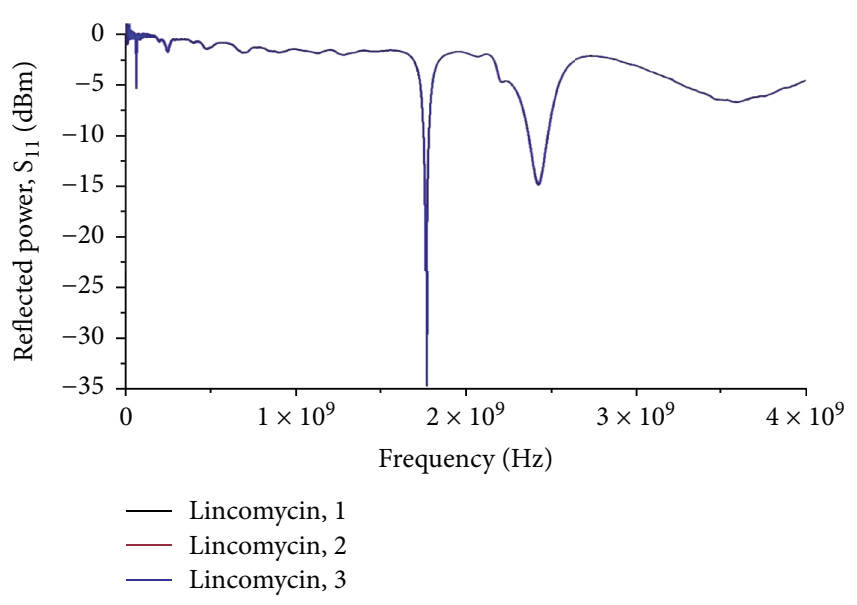

(b)

FIGURE 10: (a) Repeatability of tylosin's sample at the lowest concentration of $0.20 \mu \mathrm{g} / \mathrm{l}$ with IDE sensor using the full-range frequencies: $0 \mathrm{~Hz}-$ $1.5 \times 10^{10} \mathrm{~Hz}$; (b) repeatability of lincomycin sample at the lowest concentration of $0.25 \mu \mathrm{g} / \mathrm{l}$ with hairpin resonator sensor using the full-range frequencies: $0 \mathrm{~Hz}-4 \times 10^{9} \mathrm{~Hz}$.

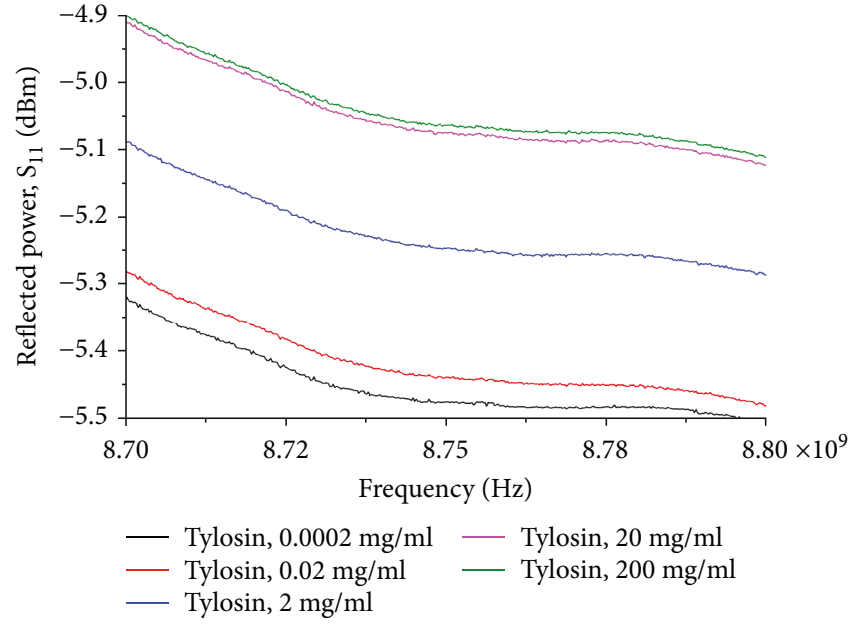

(a)
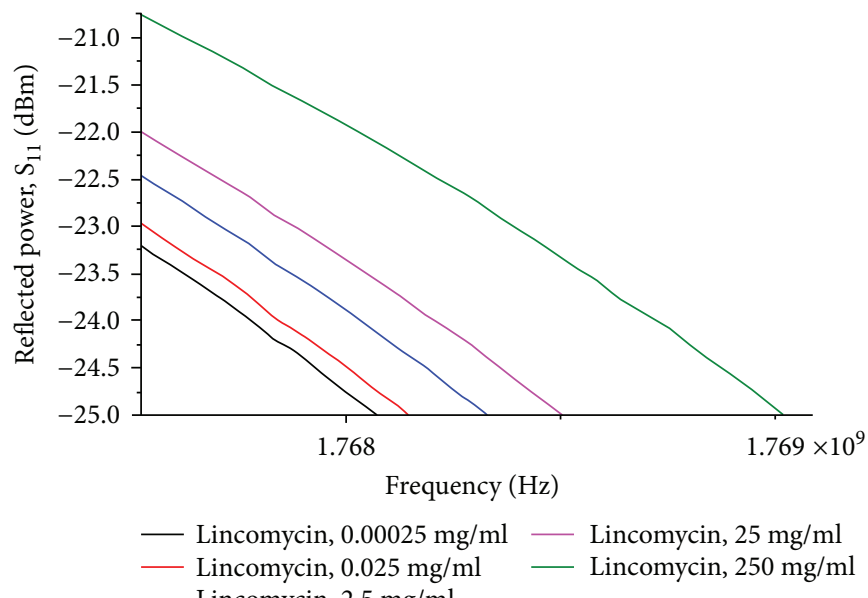

(b)

FIGURE 11: Frequencies range where the reflected $S_{11}$ signal from IDE sensor was the most sensitive to different concentrations of tylosin's samples; (b) frequencies range where the reflected signal $\mathrm{S}_{11}$ from hairpin resonator sensor was maximum for lincomycin's samples.

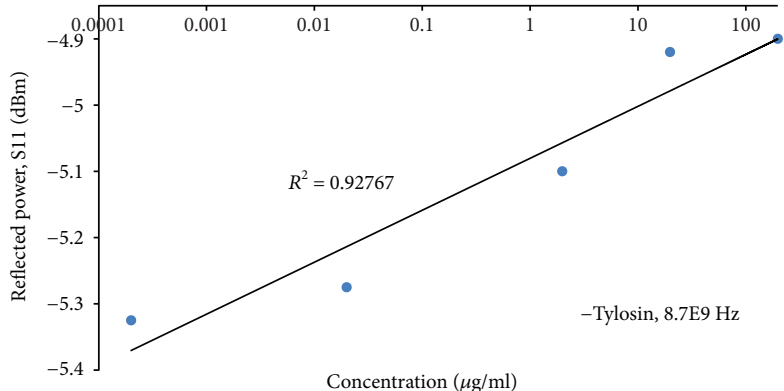

(a)

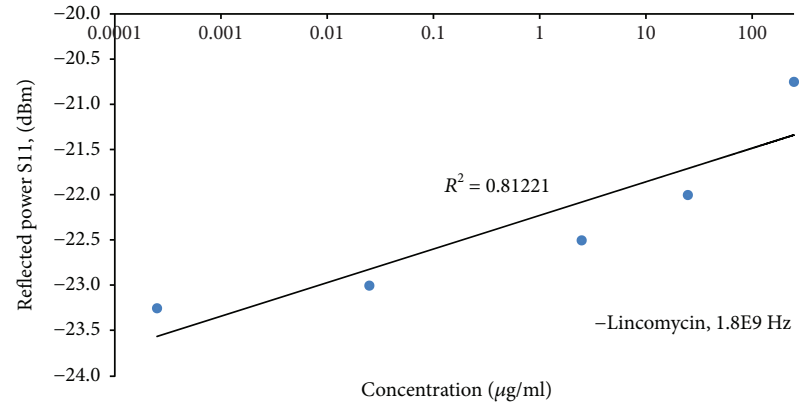

(b)

Figure 12: (a) Dependence of the $S_{11}$ transmitted microwave signal on tylosin concentration at $8.7 \times 10^{9} \mathrm{~Hz}$ recorded for $400 \mu \mathrm{l}$ solution placed in IDE sensor; (b) dependence of the $\mathrm{S}_{11}$ transmitted microwave signal on lincomycin concentration at $1.8 \times 10^{9} \mathrm{~Hz}$ recorded for $200 \mu \mathrm{l}$ solution placed in hairpin resonator sensor. 


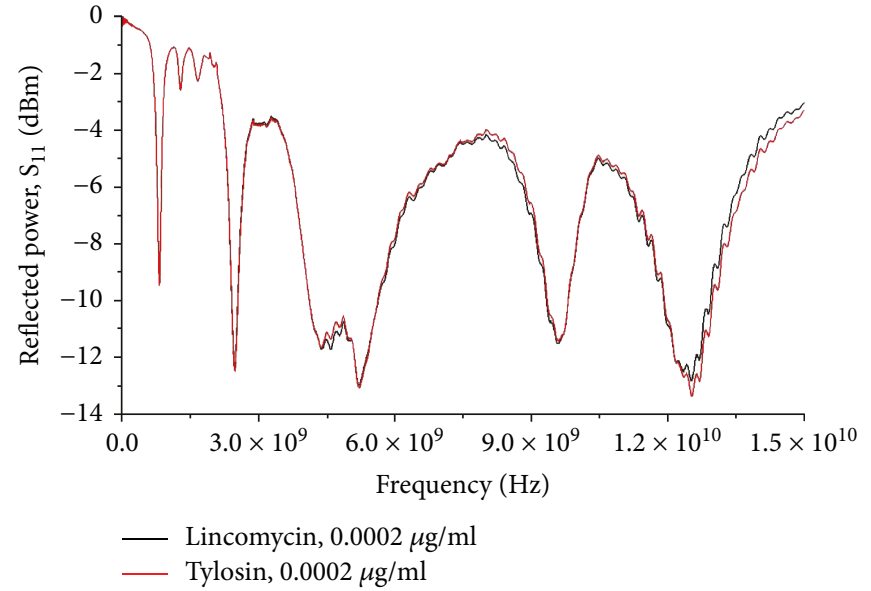

(a)

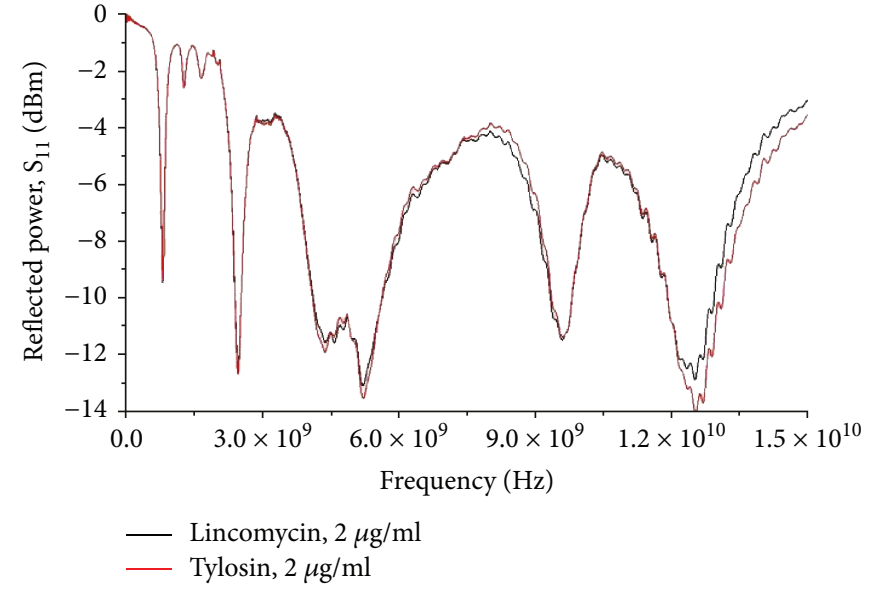

(b)

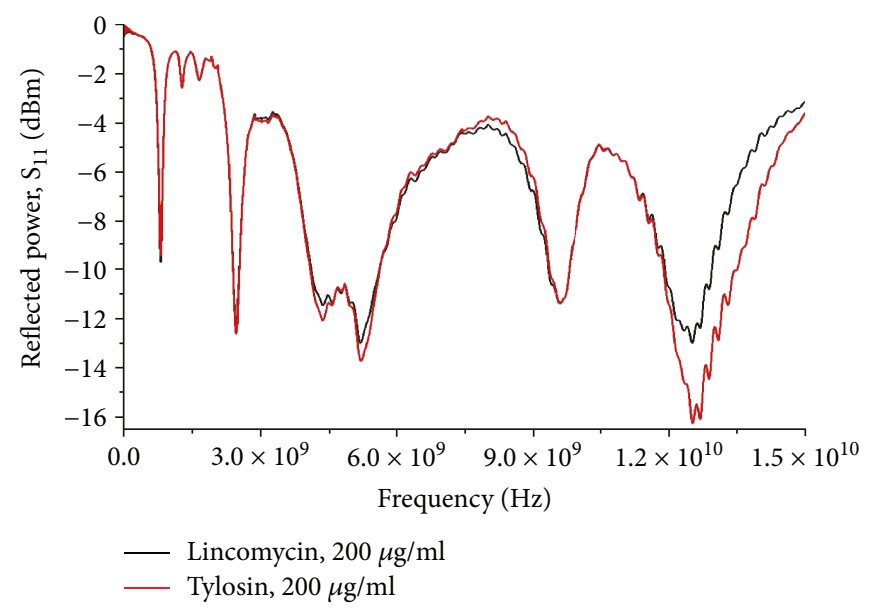

(c)

Figure 13: Difference in electromagnetic spectra of tylosin and lincomycin at (a) the lowest concentration of $0.0002 \mu \mathrm{g} / \mathrm{ml}$, (b) the middle concentration of $2 \mu \mathrm{g} / \mathrm{ml}$, and (c) the highest concentration of $200 \mu \mathrm{g} / \mathrm{ml}$.

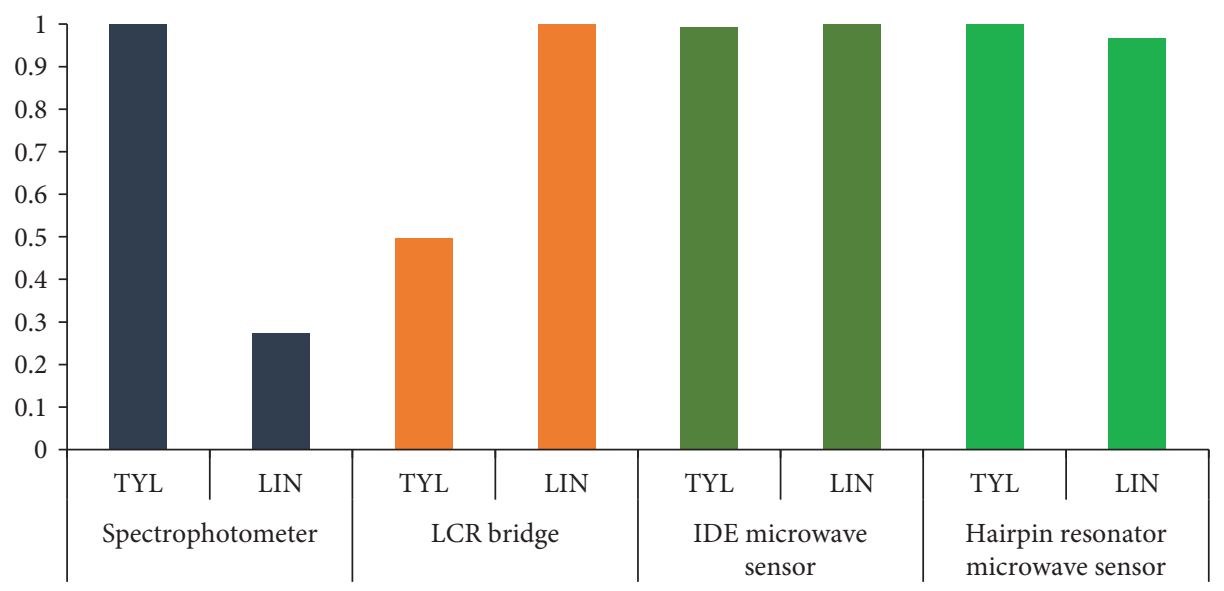

FIGURE 14: Comparison of microwave sensors, UV-Vis spectrophotometer sensor, and capacitance sensing system in the monitoring of residual concentration of tylosin and lincomycin in an aqueous solution.

IDE capacity of discriminate between tylosin and lincomycin, three samples' concentration used were $0.0002 \mu \mathrm{g} / \mathrm{ml}$, $20 \mu \mathrm{g} / \mathrm{ml}$, and $200 \mu \mathrm{g} / \mathrm{ml}$; that are, respectively, the lowest, the highest, and the middle concentrations. The region in the graph where the distinction is greater is from $1.2 \times 10^{10} \mathrm{~Hz}$ to $1.5 \times 10^{10} \mathrm{~Hz}$. 
As above results show, each method has a capability to detect the presence of antibiotics with varying degree of sensitivity. Optical spectrophotometry and capacitive measurements are adequate for higher concentrations of antibiotics, whereas to measure lower doses, as those routinely found in water sources, microwave sensors showed more promise. However, to achieve the highest possible resolution when assessing the water parameters in real-time, it is feasible to use all of these techniques in a unified sensing platform, but only selecting the specific frequency range, which provides the best results for each system. If the response of each system is calibrated for the selected frequencies as discussed above, one can produce a signal pattern, which will be specific for the residual antibiotic detected in water. Using the pattern presented in Figure 14, one can see the unified response of all the sensing methods to $0.02 \mu \mathrm{g} / \mathrm{ml}$ concentration of tylosin and lincomycin. Thus, the type and concentration of antibiotics are clearly distinguished.

The concentration monitoring through the microwave sensors presents promising results; in particular, the IDE sensor for tylosin and the hairpin resonator sensor for lincomycin showed that the reflected signal was strongly dependant on the amount of antibiotic present in water, even at doses below legally permissible in wastewater. Moreover, the IDE sensors permit an easily discrimination between the two antibiotics for all the concentration range used. Regarding the $\mathrm{UV}$-Vis spectrophotometer technique, the results obtained are extremely valuable for what concerns the detection of the different samples' concentration for a single antibiotic, though it is not possible to recognize the two antibiotics especially at low concentration. The last tested technique, the capacitance sensing system, showed the best results for monitoring residual concentration of the antibiotics in an aqueous solution and good results also about the discrimination of the tylosin and lincomycin. Notably, the fusion of all the methods into a novel sensing platform could be a key for sustainable environmental monitoring.

\section{Conclusion}

This paper reported on feasibility of using novel electromagnetic wave spectroscopy, UV-Vis spectrophotometry, and capacitance sensing system for the real-time detection and quantification of tylosin and lincomycin antibiotics in water. Each technique was assessed independently in its ability to monitor the presence and type of antibiotics in water in real time. Notably, to provide for adequate environmental safety platform, capable of detecting antibiotics even below the doses normally found in wastewater, the approach of utilizing all three techniques at once, sensor fusion was applied. This is due to the fact that each sensing method showed a varying degree of sensitivity and selectivity to the tested antibiotic solutions, and only by combining the best features of all the devices, the efficient monitoring solution was offered. In particular, the high response to the different solutions of antibiotics was illustrated by planar IDE microwave sensor for tylosin, whereas hairpin resonator microwave sensor was more sensitive to lincomycin. Capacitance sensor was able to differentiate both antibiotics, but at higher doses. It is strongly believed that the reported approach, where the response of each device to a sample of water polluted with antibiotic is treated as a response signature pattern, is feasible as a basis for a universal real-time water environment management system to tackle antibiotic resistance.

\section{Data Availability}

Data is available according to the standard procedure to retain data from scientific studies for a period of up to 7 years. Access to this data may be requested via the corresponding author.

\section{Conflicts of Interest}

The authors declare that they have no conflicts of interest.

\section{References}

[1] J. Gallagher and C. MacDougall, Antibiotics Simplified, Jones \& Bartlett Publishers, 2011.

[2] V. O. Stockwell and B. Duffy, "Use of antibiotics in plant agriculture," Revue Scientifique et Technique, vol. 31, no. 1, pp. 199-210, 2012.

[3] Center for Disease Dynamics, Economics \& Policy, The State of the World's Antibiotics 2015, CDDEP, 2015.

[4] J. O'Neill, Tackling Drug-Resistant Infections Globally: Final Report and Recommendations, HM Government and Welcome Trust, 2016.

[5] O. Mahjoub, A. Dahchour, and C. Siebe, Emerging Pollutants in Irrigation Water: Origins, Fate, Risks, and Mitigation, 2015.

[6] WHO, Global Report on Surveillance 2014, WHO, 2014.

[7] F. Baquero, J.-L. Martinez, and R. Canton, "Antibiotics and antibiotic resistance in water environments," Current Opinion in Biotechnology, vol. 19, no. 3, pp. 260-265, 2008.

[8] A. L. Batt, S. Kim, and D. S. Aga, "Comparison of the occurrence of antibiotics in four full-scale wastewater treatment plants with varying designs and operations," Chemosphere, vol. 68, no. 3, pp. 428-435, 2007.

[9] O. Korostynska, A. Mason, A. Al-Shamma'a, W. Jansomboon, and S. Boontanon, "Real-time detection of residual antibiotics concentration with microwave cavity and planar EM sensors," in 2015 9th International Conference on Sensing Technology (ICST), pp. 492-495, Auckland, New Zealand, December 2015.

[10] M. Soprani, O. Korostynska, A. Mason et al., "Low-frequency capacitive sensing for environmental monitoring of water pollution with residual antibiotics," in 2016 9th International Conference on Developments in eSystems Engineering (DeSE), pp. 317-322, Liverpool, UK, 2016.

[11] S. Khaliq, N. Rashid, K. Akhtar, and M. A. Ghauri, "Production of tylosin in solid-state fermentation by Streptomyces fradiae NRRL-2702 and its gamma-irradiated mutant $(\gamma-1)$," Letters in Applied Microbiology, vol. 49, no. 5, pp. 635-640, 2009.

[12] S. Giguère, J. F. Prescott, J. D. Baggot, R. D. Walker, and P. M. Dowling, Antimicrobial Therapy in Veterinary Medicine, John Wiley \& Sons, Inc., 2007.

[13] A. J. Macleod, H. B. Ross, R. L. Ozere, G. Digout, and C. van Rooyen, "Lincomycin: a new antibiotic active against staphylococci and other gram-positive cocci," Canadian Medical Association Journal, vol. 91, no. 20, pp. 1056-1060, 1964. 
[14] L. H. Keri, B. M. Thomas, and R. C. Joel, "Mobility of tylosin and enteric bacteria in soil columns," in Fate of Pharmaceuticals in the Environment and in Water Treatment Systems, pp. 167-178, CRC Press, 2007.

[15] K. G. Karthikeyan and M. T. Meyer, "Occurrence of antibiotics in wastewater treatment facilities in Wisconsin, USA," Science of the Total Environment, vol. 361, no. 1-3, pp. 196-207, 2006.

[16] World Health Organization, Pharmaceuticals in DrinkingWater, WHO, 2012.

[17] K. D. Brown, J. Kulis, B. Thomson, T. H. Chapman, and D. B. Mawhinney, "Occurrence of antibiotics in hospital, residential, and dairy effluent, municipal wastewater, and the Rio Grande in New Mexico," Science of the Total Environment, vol. 366, no. 2-3, pp. 772-783, 2006.

[18] P. Qiu, X. Guo, N. Wang, X. Kong, and H. He, "Simultaneous determination of ten antibiotics in pharmaceutical wastewater using ultra-high performance liquid chromatography-tandem mass spectrometry," Chinese Journal of Chromatography, vol. 33, pp. 722-729, 2015.

[19] T. Schwartz, W. Kohnen, B. Jansen, and U. Obst, "Detection of antibiotic-resistant bacteria and their resistance genes in wastewater, surface water, and drinking water biofilms," FEMS Microbiology Ecology, vol. 43, no. 3, pp. 325-335, 2003.

[20] A. Lupo, S. Coyne, and T. U. Berendonk, "Origin and evolution of antibiotic resistance: the common mechanisms of emergence and spread in water bodies," Frontiers in Microbiology, vol. 3, 2012.

[21] P. Gayen and B. P. Chaplin, "Selective electrochemical detection of ciprofloxacin with a porous nafion/multiwalled carbon nanotube composite film electrode," ACS Applied Materials \& Interfaces, vol. 8, no. 3, pp. 1615-1626, 2016.

[22] D. Hu, B. Fulton, K. Henderson, and J. Coats, "Identification of tylosin photoreaction products and comparison of ELISA and HPLC methods for their detection in water," Environmental Science \& Technology, vol. 42, no. 8, pp. 2982-2987, 2008.

[23] E. Nyfors, "Industrial microwave sensors-a review," Subsurface Sensing Technologies and Applications, vol. 1, no. 1, pp. 23-43, 2000.

[24] J.-S. Hong and M. J. Lancaster, "Cross-coupled microstrip hairpin-resonator filters," IEEE Transactions on Microwave Theory and Techniques, vol. 46, no. 1, pp. 118-122, 1998.

[25] O. Korostynska, M. Ortoneda-Pedrola, A. Mason, and A. I. AlShamma'a, "Flexible electromagnetic wave sensor operating at $\mathrm{GHz}$ frequencies for instantaneous concentration measurements of $\mathrm{NaCl}, \mathrm{KCl}, \mathrm{MnCl}_{2}$ and $\mathrm{CuCl}$ solutions," Measurement Science and Technology, vol. 25, no. 6, article 065105, 2014.

[26] O. Korostynska, A. Mason, and A. I. Al-Shamma'a, "Flexible electromagnetic wave sensors for real-time assessment of water contaminants," in Sensing Technology: Current Status and Future Trends I, A. Mason, S. C. Mukhopadhyay, K. P. Jayasundera, and N. Bhattacharyya, Eds., vol. 7, pp. 99-115, Springer International Publishing, 2014.

[27] E. Terzic, R. Nagarajah, and M. Alamgir, "A neural network approach to fluid quantity measurement in dynamic environments," Mechatronics, vol. 21, no. 1, pp. 145-155, 2011.

[28] H. Kuttruff, Ultrasonics: Fundamentals and Applications, Elsevier, 2012.
[29] W. Bolton, “Capacitance," in Engineering Science, pp. 156-167, Elsevier, 2006.

[30] R. A. Serway and J. W. Jewett, "Capacitance and dielectrics," in Physics for Scientists and Engineers, pp. 796-820, ThomsonBrooks/Cole, 2004. 


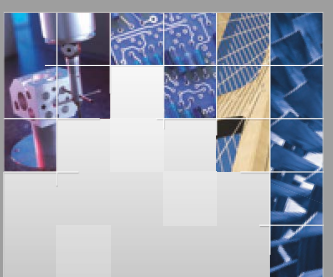

\section{Enfincering}
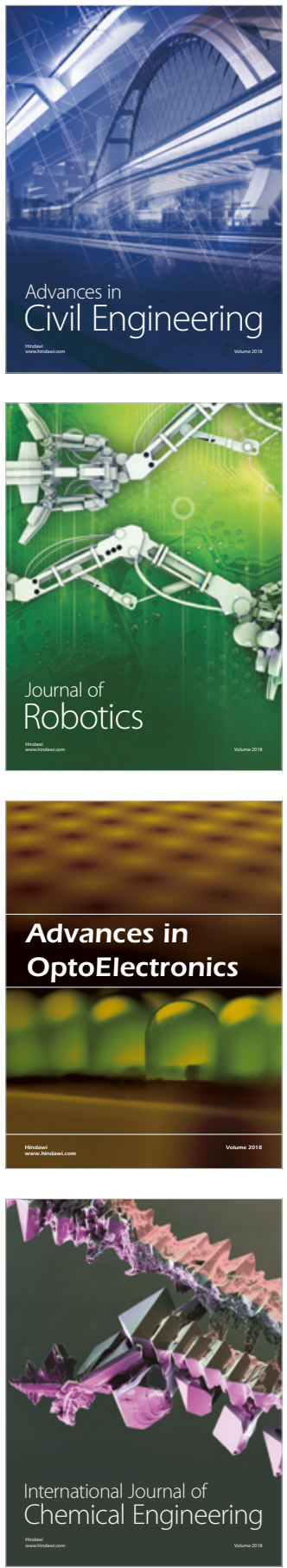

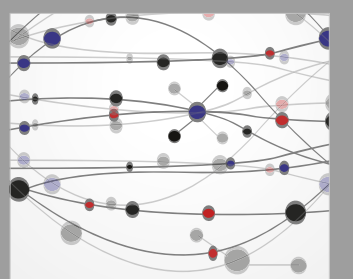

\section{Rotating \\ Machinery}

The Scientific World Journal

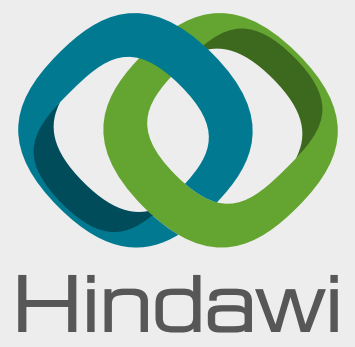

Submit your manuscripts at

www.hindawi.com
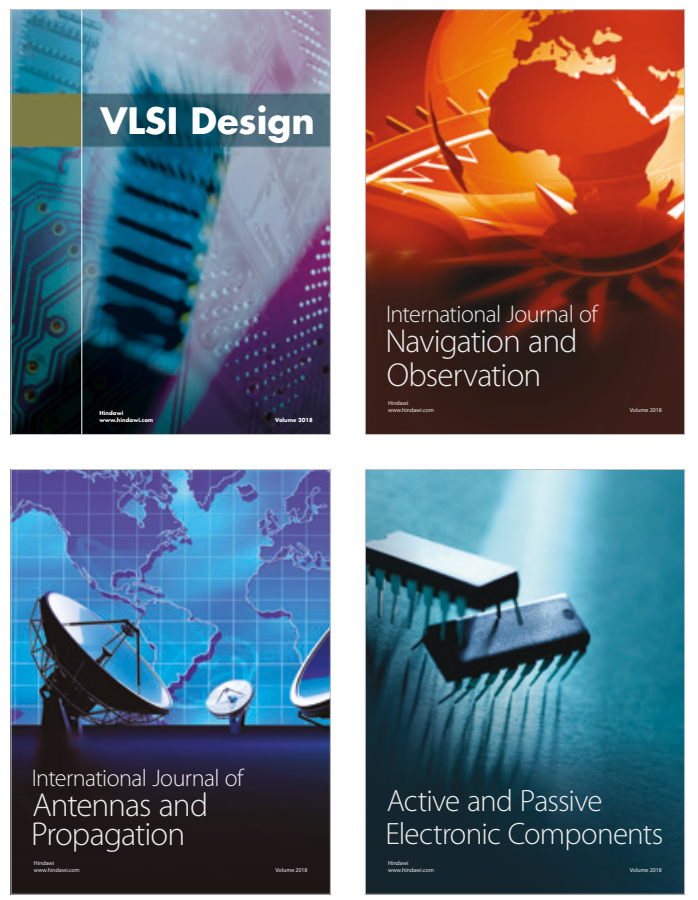
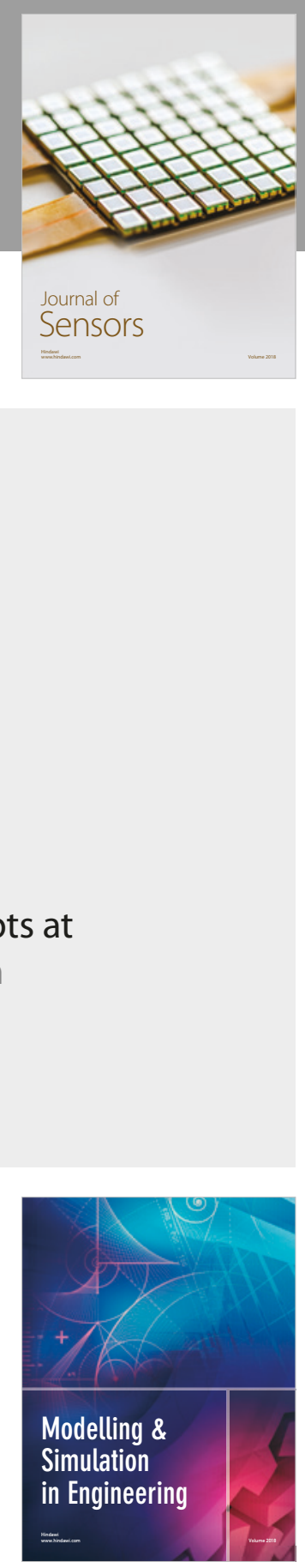

\section{Advances \\ Multimedia}
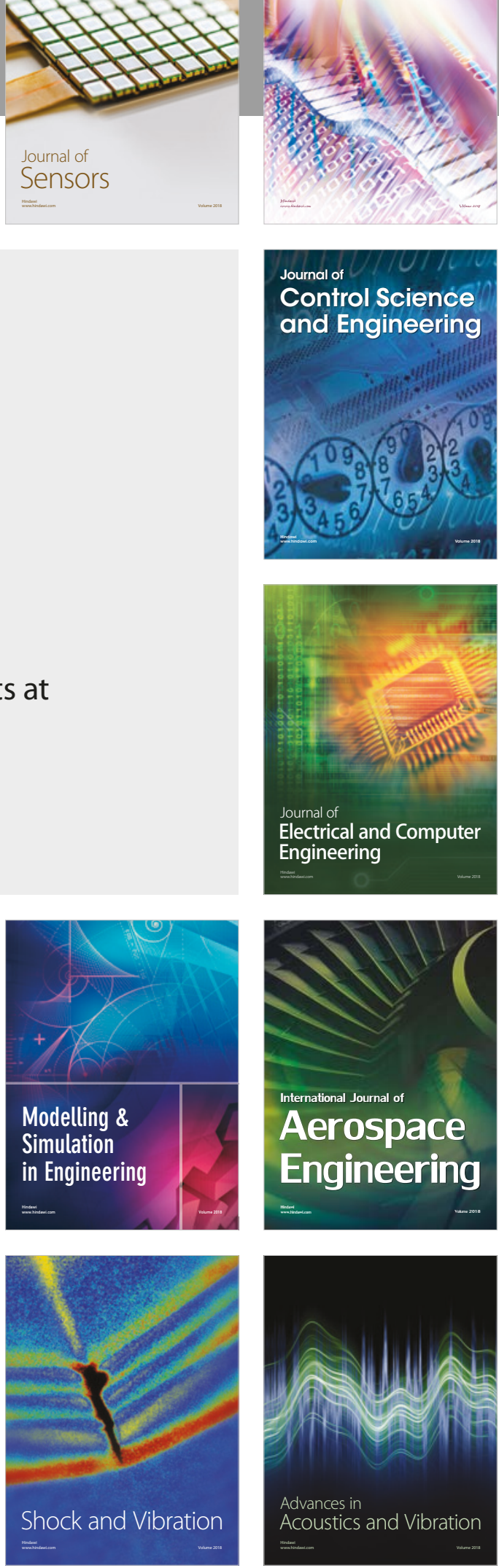